\title{
To study opinion regarding necessity of marriage among female of the Mehsana and Ahmadabad city
}

\author{
Neeta P. Chaudhari, Jiju N. Vyas and Neha Tiwari
}

Received: 02.04.2019; Revised: 03.10.2019; Accepted: 17.10.2019

See end of the paper for authors' affiliations Neha Tiwari

Krishi Vigyan Kendra (J.A.U.), Amerli (Gujarat) India

Email : nehatiwari@jau.in
ABSTRACT : The present study was conducted in Mehsana (urban and rural area) and Ahmadabad (urban and rural area) city. The sample size was 720 women and they were selected from both the cities. The women who were educated upto $12^{\text {th }}$ standard, graduate and post graduate were randomly selected for the study. Purposive random sampling technique was used for selection of the sample. The research design for the present paper was two pronged approach. A descriptive survey with pre-tested, validated interview schedule was used to acquire the information needed for knowing ideas about opinion of marriage.

KEY WORDS: Women, Marriage, Opinion, Education, Goals of marriage

- HOW TO CITE THIS PAPER : Chaudhari, Neeta P., Vyas, Jiju N. and Tiwari, Neha (2019). To study opinion regarding necessity of marriage among female of the Mehsana and Ahmadabad city. Asian J. Home Sci., 14 (2) : 269-274, DOI: 10.15740/HAS/AJHS/14.2/269-274. Copyright@ 2019: Hind Agri-Horticultural Society. 